ERRATA

Mycopathologia, vol. 58 , no. 1, pp. $39-47$

\title{
ON THE FUNGITOXICITY OF SOME NEW THIOCYANATOPYRAZOLE DERIVATIVES: ELECTRON MICROSCOPICAL STUDY IN TRICHOPHYTON MENTAGROPHYTES
}

\author{
Gian Luigi Vannini, Giuseppe Dall'Olio \& Paolo Giori
}

Page 45, right-hand column, lines $24-37$ should read:

... 'This interpretation is re-enforced by the identical basic resolvable structure following GA-TAPO-OsO $\mathrm{O}_{4}$ fixation of the plasmalemma and the polimembranous bodies, a fact that would suggest a close analogy in their chemical composition. Since TAPO has a strong capability to react with the polisaccharides (25), it is possible that these membranes are richer than the inner ones in glucidic components, i.e. glycoproteins and glycolipids. It may also be true that the aspects caused by a prolonged treatment (plasmolysis, generalized lysis with emptying of the apical cells) could result from the primary effects of the molecule on the various membranes, whose integrity is essential to many of the vital cell functions.' .. . 